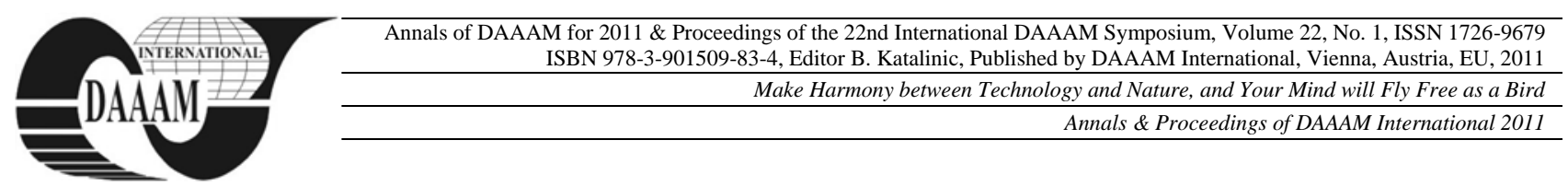

\title{
REGIONS OF STABILITY FOR PID CONTROLLERS
}

\author{
MATUSU, R[adek]
}

\begin{abstract}
This contribution deals with calculating and plotting the stability regions for Proportional-Integral-Derivative (PID) controllers. The region of possible placement of the PID controller parameters which assure feedback stabilization of a controlled system is obtained by means of the Tan's method. This technique is based on plotting the stability boundary locus in various planes of the P-I-D space. Possible application is shown on an illustrative example where a third order plant is stabilized
\end{abstract}

Key words: PID Controllers, stability regions, stabilization

\section{INTRODUCTION}

An overwhelming majority of nowadays practical industrial control applications employs PI(D) compensators ( Hägglund, 1995). For that reason, the investigation on appropriate design methods for PID controllers is still very topical (O`Dwyer, 2003), especially if these controllers are able to cope with plants under various nonlinearities, perturbations or time-variability. However, the primary and essential requirement consists in ensurance of closed-loop stability.

There are a number of methods for computation of stabilizing PI(D) controllers in literature - e.g. calculation technique presented in (Söylemez et al., 2003), Tan's stability boundary locus approach from (Tan \& Kaya, 2003; Tan et al., 2006) or method based on Kronecker summation published in (Fang et al., 2009). Application of the last two stabilization techniques, even from the robust stability viewpoint, has been already analyzed e.g. in (Matušů, 2008; Matušů \& Prokop, 2010; Matušů, 2011a; Matušů, 2011b);

The contribution presents various approaches to plotting the 3-D stability regions in P-I-D space on the basis of Tan's stability boundary locus method (Tan et al., 2006). It partially draws upon the previously published works, especially (Matušů, 2011a) and (Matušů, 2011b). The applicability of described methodology is demonstrated on an illustrative example - stabilization of a third order plant.

\section{CALCULATION OF STABILITY REGIONS}

Assume a conventional feedback control loop with a controlled plant:

$$
G(s)=\frac{b(s)}{a(s)}
$$

and with an ideal PID controller:

$$
C(s)=k_{P}+\frac{k_{I}}{s}+k_{D} s=\frac{k_{P} s+k_{I}+k_{D} s^{2}}{s}
$$

A possible approach for computation of all possible parameters of the PID controller which guarantee closed-loop stability has been published in (Tan et al., 2006). Besides, its simplified version suitable for PI controllers with additional embellishment also for interval controlled systems can be found e.g. in (Tan \& Kaya, 2003). The method is based on plotting the stability boundary locus. As the first step, the substitution $s=j \omega$ in (1) and consequent decomposition of the numerator and denominator into their even and odd parts results in:

$$
G(j \omega)=\frac{b_{E}\left(-\omega^{2}\right)+j \omega b_{O}\left(-\omega^{2}\right)}{a_{E}\left(-\omega^{2}\right)+j \omega a_{O}\left(-\omega^{2}\right)}
$$

Subsequently, computation of closed-loop characteristic polynomial and setting the real and imaginary parts to zero lead to equations for proportional and integral gains (Tan \& Kaya, 2003; Tan et al., 2006; Matušů, 2011a; Matušů, 2011b):

$$
\begin{aligned}
& k_{P}\left(\omega, k_{D}\right)=\frac{P_{5}(\omega) P_{4}(\omega)-P_{6}(\omega) P_{2}(\omega)}{P_{1}(\omega) P_{4}(\omega)-P_{2}(\omega) P_{3}(\omega)} \\
& k_{I}\left(\omega, k_{D}\right)=\frac{P_{6}(\omega) P_{1}(\omega)-P_{5}(\omega) P_{3}(\omega)}{P_{1}(\omega) P_{4}(\omega)-P_{2}(\omega) P_{3}(\omega)}
\end{aligned}
$$

where

$$
\begin{aligned}
& P_{1}(\omega)=-\omega^{2} B_{O}\left(-\omega^{2}\right) \\
& P_{2}(\omega)=B_{E}\left(-\omega^{2}\right) \\
& P_{3}(\omega)=\omega B_{E}\left(-\omega^{2}\right) \\
& P_{4}(\omega)=\omega B_{O}\left(-\omega^{2}\right) \\
& P_{5}(\omega)=\omega^{2} A_{O}\left(-\omega^{2}\right)+\omega^{2} B_{E}\left(-\omega^{2}\right) k_{D} \\
& P_{6}(\omega)=-\omega A_{E}\left(-\omega^{2}\right)+\omega^{3} B_{O}\left(-\omega^{2}\right) k_{D}
\end{aligned}
$$

Simultaneous solution of relations (4) and plotting the obtained values into the $\left(k_{P}, k_{I}, k_{D}\right)$ space define the stability boundary locus.

Note that the parameters $k_{P}$ and $k_{I}$ depend on derivative constant $k_{D}$, which is practically considered to be chosen and fixed for one set of calculations. In other words, $k_{D}$ is preset and corresponding set of boundary parameters $k_{P}, k_{I}$ is consequently calculated. The obtained curve splits the $\left(k_{P}, k_{I}\right)$ plane into the stable and unstable regions. The decision on the stabilizing/unstabilizing regions can be done via a test point within each area. Then, the final stability region(s) can be successively plotted through the " $\left(k_{P}, k_{I}\right)$ sections" in the $\left(k_{P}, k_{I}, k_{D}\right)$ space by sampling $k_{D}$.

Analogically, the stability boundary locus can be obtained by means of $\left(k_{P}, k_{D}\right)$ pairs for the sampled values of $k_{I}$. However, the third option of getting the stability boundary - in the $\left(k_{I}, k_{D}\right)$ plane for a fixed value of $k_{P}$ - is not so straightforward because of division by zero. Nevertheless, the 
technique presented in (Tan et al., 2006), which concurs with linear programming based approach from (Ho et al., 1997), can be utilized.

\section{ILLUSTRATIVE EXAMPLE}

Consider a third order controlled plant which has been already used in (Matušů \& Prokop, 2010) and which is given by transfer function:

$$
G(s)=\frac{5}{s^{3}+2 s^{2}+3 s+4}
$$

It means that the even and odd parts from the transfer function (3) are:

$$
\begin{aligned}
& B_{E}\left(-\omega^{2}\right)=5 \\
& B_{O}\left(-\omega^{2}\right)=0 \\
& A_{E}\left(-\omega^{2}\right)=2\left(-\omega^{2}\right)+4 \\
& A_{O}\left(-\omega^{2}\right)=-\omega^{2}+3
\end{aligned}
$$

First, the stability regions were calculated according to equations (4) and (5) (and bottomed by lines $k_{I}=0$ ) for 41 equally spaced values of $k_{D}$ from 0 to 1 and visualized in fig. 1. As can be verified, all the variations of PID controller parameters which are located inside the shape defined by stability regions from fig. 1 guarantee the feedback stabilization of the plant (6).

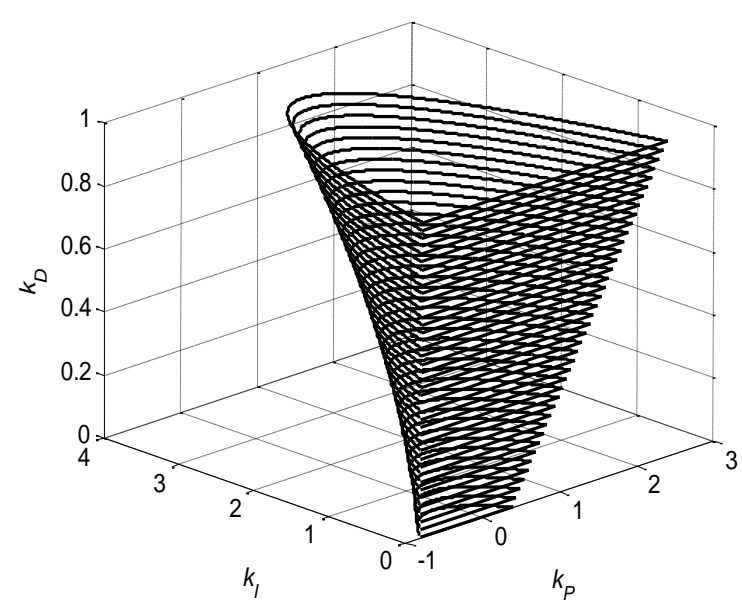

Fig. 1. Regions of stability for plant (6) and for $k_{D} \in\langle 0,1\rangle$

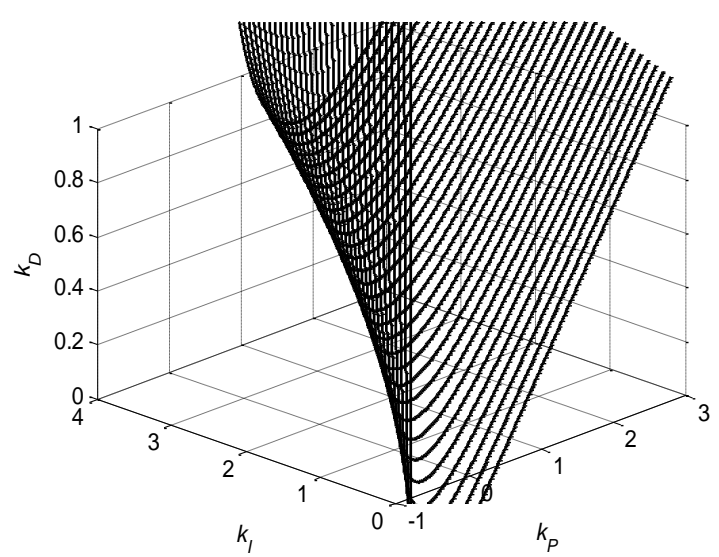

Fig. 2. Regions of stability for plant (6) and for $k_{I} \in\langle 0,3\rangle$
Then, the stabilizing regions were computed alternatively by cutting the sections in $\left(k_{P}, k_{D}\right)$ plane for 31 equally spaced values of $k_{I}$ from 0 to 3 . The obtained results are shown in fig. 2. The final 3-D stability regions from both fig. 1 and fig. 2 cover the same area.

\section{CONCLUSION}

The contribution was mainly intended to present various approaches to computing and consequent plotting the 3-D stability regions in P-I-D space. The applied idea has been based on Tan's stability boundary locus technique (Tan et al., 2006). In the illustrative example, the final stability region for PID controller and the third order controlled plant was obtained first using " $\left(k_{P}, k_{I}\right)$ sections" for fixed samples of $k_{D}$ and then by means of " $\left(k_{P}, k_{D}\right)$ sections" for sampled values of $k_{I}$.

\section{ACKNOWLEDGEMENTS}

The work was supported by the Ministry of Education, Youth and Sports of the Czech Republic under the Research Plan No. MSM 7088352102 and by the European Regional Development Fund under the project CEBIA-Tech No. CZ.1.05/2.1.00/03.0089. This assistance is very gratefully acknowledged.

\section{REFERENCES}

Åström, K. J. \& Hägglund, T. (1995). PID Controllers: Theory, Design and Tuning, Instrument Society of America, Research Triangle Park, North Carolina, USA

Fang, J.; Zheng, D. \& Ren, Z. (2009). Computation of stabilizing PI and PID controllers by using Kronecker summation method. Energy Conversion and Management, Vol. 50, No. 7, pp. 1821-1827

Ho, M. T.; Datta, A. \& Bhattacharyya, S. P. (1997). A linear programming characterization of all stabilizing PID controllers, In: Proceedings of the American Control Conference, Albuquerque, New Mexico, USA

Matušů, R. \& Prokop, R. (2010). Two Approaches to Computation of Stabilizing PI Controllers, In: Proceedings of the 21st International DAAAM Symposium, Zadar, Croatia, pp. 487-488

Matušů, R. (2008). Robust Stabilization of Interval Plants Using PI Controllers, In: Proceedings of the 19th International DAAAM Symposium, Trnava, Slovakia, pp. 831-832

Matušù, R. (2011a). Computation of Stability Regions for PID Controllers, In: Proceedings of the 10th WSEAS International Conference on Signal Processing, Robotics and Automation, Cambridge, UK, pp. 210-213

Matušù, R. (2011b). Calculation of all stabilizing PI and PID controllers. International Journal of Mathematics and Computers in Simulation, Vol. 5, No. 3, pp. 224-231

O`Dwyer, A. (2003). Handbook of PI and PID Controller Tuning Rules, Imperial College Press, London, UK

Söylemez, M. T.; Munro, N. \& Baki, H. (2003). Fast calculation of stabilizing PID controllers. Automatica, Vol. 39, No. 1, pp. 121-126

Tan, N. \& Kaya, I. (2003). Computation of stabilizing PI controllers for interval systems, In: Proceedings of the 11th Mediterranean Conference on Control and Automation, Rhodes, Greece

Tan, N.; Kaya, I.; Yeroglu, C. \& Atherton, D. P. (2006). Computation of stabilizing PI and PID controllers using the stability boundary locus. Energy Conversion and Management, Vol. 47, No. 18-19, pp. 3045-3058 